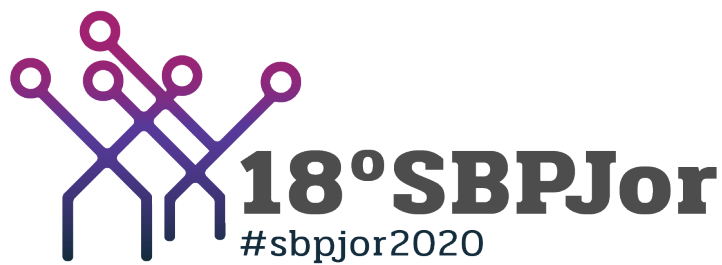

\section{Repertórios de Esperança e de Solidariedade: uma Análise de Conteúdo do Portal Positive News}

\author{
Guilherme Lucian ${ }^{1}$ \\ Ângela Teixeira de Moraes $^{2}$ \\ Universidade Federal de Goiás, pesquisador. \\ Universidade Federal de Goiás, docente.
}

Resumo: Este estudo é demarcado pela busca por novos roteiros de sentido na interface epistemológica entre comunicação, jornalismo e cidadania, e interroga até que ponto o relato das jornadas cívicas pode sinalizar a esperança ao cidadão numa época de incertezas. Realizou-se uma análise de conteúdo de 30 matérias publicadas pelo portal britânico Positive News durante os meses de março a julho de 2020 (período correspondente à "primeira onda" de contágio do novo coronavírus), e como resultado foram criadas quatro classes que situam a questão da solidariedade humana no horizonte ético da profissão.

Palavras-chave: Jornalismo construtivo; comunicação; cidadania; esperança; solidariedade.

\section{Noções introdutórias}

Não há escuridão tão densa que persista quando à volta esplandecem quaisquer bocados de luz. É com essa proposição - um tanto ingênua, porém bonita em sua consistência - que nos atrevemos a iniciar este texto. Se é possível traduzir em termos

\footnotetext{
${ }^{1}$ Doutorando em Comunicação na Faculdade de Informação e Comunicação da Universidade Federal de Goiás e acadêmico de Psicologia na Faculdade de Educação dessa mesma instituição. Brasil, Goiás, Goiânia. E-mail: guilhermelucian@discente.ufg.br

${ }^{2}$ Prof $^{\mathrm{a}}$. Dr ${ }^{\mathrm{a}}$. no Curso de Jornalismo da Faculdade de Informação e Comunicação da Universidade Federal de Goiás e no Programa de Pós-Graduação em Comunicação dessa instituição. Brasil, Goiás, Goiânia. E-mail: prof.atmoraes@gmail.com
} 
sensíveis o horror de nossa atual circunstância, projetando-os à realidade discursiva do jornalismo, diríamos então que não há melhor solução senão a (re)invenção da esperança; com tudo o que está aí pressuposto: o reforço da confiança em face do que ainda é turvo às vistas, a promessa de que as sombras se desfaçam e a entrega sincera à expectativa que precede o salto de fé num abismo cujo fundo parece ser menos confuso quando comparado às suas beiradas. Devido à crise pandêmica do novo coronavírus ${ }^{3}$, algumas instituições jornalísticas mobilizam esforços para construir uma trama de narrativas que revivam, ou que ao menos acendam timidamente, os ânimos sociais.

À primeira vista parece absurda a ideia de haver na palavra do jornalismo a ressonância explícita da esperança, pois nos acostumamos a crer (e sustentar como ideal) que em seus ecos se estendem apenas os tons da dimensão mais fria e apática dos eventos do mundo, ou, quando muito, tão-somente a urgência de servir como instrumento de mediação às histórias do cotidiano (RODRIGUES, 1999) ${ }^{4}$. Se lhe há quaisquer inclinações a enredos ilocucionários - isto é, a estruturas de sentido proposicionais e diretivas projetadas à escuta e à ação —, diluem-se então para dar relevo à sua função mais óbvia, qual seja: a de operar como cadeia neutra de (re)transmissão (HACKETT, 1999) das conversas sociais. Por princípio, porém, há em sua linguagem o necessário à criação de repertórios orientados à formação da pessoa humana; e nisto está pressuposto o amparo solidário ao cidadão. A segurança de seu modelo funcional parece agora desequilibrar-se diante do potencial discursivo de uma normatividade que é reavida para ofertar um mínimo de alento às sociedades confinadas em decorrência do avanço da pandemia. Reavida porque, se refletirmos, esteve sempre à mira do horizonte ético da análise de jornadas uma articulação em relação a bases vinculativas com a esfera cívica.

Nem todo repertório jornalístico traz à superfície os sussurros da esperança, sim, mas ao menos se adensa na formação de estruturas cognitivas singulares para repercutir memórias e tentar ressoar, tanto quanto lhe for possível, as ternuras de uma época. Isto

\footnotetext{
${ }^{3}$ Uma cepa recém-descoberta do coronavírus SARS-Cov-2 (Síndrome Respiratória Aguda Grave 2), cuja transmissão se realiza por meio de secreções respiratórias, tais como gotículas suspensas no ar quando uma pessoa infectada tosse ou espirra. Seu contágio foi crítico o bastante a ponto de se tornar pandêmico durante o primeiro semestre de 2020, e até a escrita deste texto, nenhuma vacina foi disponibilizada às populações.

${ }^{4}$ Cf. RODRIGUES, A. D. O acontecimento. In: TRAQUINA, N. Jornalismo: questões, teorias e "estórias". 2. ed. Lisboa: Vega, 1999. Cap. 1, p. 27-33.

${ }^{5}$ Cf. HACKETT, R. Declínio de um paradigma? A parcialidade e a objectividade nos estudos dos media noticiosos. In: TRAQUINA, N. Jornalismo: questões, teorias e “estórias”. 2. ed. Lisboa: Vega, 1999. Cap. 7, p. 101-130.
} 
SBPJor - Associação Brasileira de Pesquisadores em Jornalismo

$18^{\circ}$ Encontro Nacional de Pesquisadores em Jornalismo

3 a 6 de Novembro de 2020

porque suas palavras não se configuram como aquelas que cruzam o arcabouço de sentidos de outras instituições sociais, já que lhe há, na medida do alcance, um léxico que se circunscreve para além da busca da verdade ou da imparcialidade ideologizadas. Se é provável que suas pronúncias sirvam de consolo às pessoas em tempos de desamparo, portanto, nada mais natural que sejam então abertas as clareiras para uma narrativa em cujo núcleo serão entrelaçadas as pretensões da bondade, da amabilidade e as da crença em um destino menos sombrio quando tudo à volta aponta ao contrário.

É nesse ponto que o campo jornalístico tem se disposto não apenas a reumanizar as pautas que ordenam os diálogos cívicos, mas sobretudo a ofertar amparo à pessoa humana por sentir que há nisto um senso de urgência e de dever pareados aos princípios de seu sistema de ideias. Trata-se de dar sentido à moldura da vida, isto é, de indicar um rumo seguro à composição das tramas que de algum modo nos são caras à união de todos com todos. Essa mudança qualitativa na relação e na experiência do cidadão com as instituições jornalísticas - isto quando não vistas apenas segundo a sua configuração organizacional - há de servir talvez como um sinal de luz no horizonte, porque daí despontam os traços de palavras formativas que amparam, que acarinham e que com sua ressonância firmam pontes a um encontro de humanidades.

Se, por um lado, o modelo de desenvolvimento do jornalismo de referência segue à risca o receituário do capital - o qual se ancora no constante (re)investimento do lucro sobre a produção das próprias narrativas - , por outro, é possível mobilizar esforços para além da lógica do valor de troca, pois à tessitura de sua palavra não são apagados os indícios de amor e de ternura quando traduzidos pela linguagem distintiva do dinheiro. É certo que algumas das relações sócio-intersubjetivas foram aos poucos substituídas por contextos funcionais (HABERMAS, 1998), mas essa configuração, por si só, não afasta o jornalismo de uma autoconsciência reveladora, isto é, de um processo mais ou menos cíclico que permite àqueles que gravitam em torno da sua estrutura institucional o reconhecimento no resultado de seu trabalho, porque do contrário pouco restaria senão um esforço que se torna estranho a si mesmo (afastado de seu propósito, seja este qual for). E por mais que o padrão à composição de um quadro referencial derive de princípios mercadológicos, seu discurso legitimador permanece orientado ao compromisso com o cidadão, e como tal se adensam os seus fundamentos ético-normativos. 
SBPJor - Associação Brasileira de Pesquisadores em Jornalismo

$18^{\circ}$ Encontro Nacional de Pesquisadores em Jornalismo

3 a 6 de Novembro de 2020

Isso posto, resta-nos estabelecer as devidas condições para encontrar no repertório de palavras jornalísticas a ressonância comunicacional da esperança, isto é, o sussurro de abertura à humanidade que ampara e que conforta o cidadão. Interessa-nos encontrar um ponto de ancoragem social à questão do afeto, articulando-a até onde se mostrar possível em função do léxico evidenciado durante a pandemia da Covid-19. Este texto, aliás, é a extensão de um estudo maior em andamento, e é demarcado pela busca de novos roteiros à vida na interface epistemológica entre comunicação, jornalismo e cidadania, pretendendo-se a questionar em que medida o relato das jornadas cívicas pode servir de alento às pessoas em uma época de incertezas e de angústias.

Propomos uma análise de conteúdo de 30 matérias publicadas pelo portal britânico Positive News ${ }^{6}$ nos meses de março a julho de 2020 — período correspondente ao que se convencionou chamar de "primeira onda" de contágio do coronavírus. Trata-se de um portal de jornalismo construtivo que serve de extensão à revista de mesmo nome, e que se caracteriza por direcionar sua abordagem informativa às soluções sociais. Foi fundado em 2015 com financiamento colaborativo, e sua publicação impressa circula pela Grã-Bretanha por meio de uma assinatura anual de 30 euros.

Figura 1 - Página de uma das matérias analisadas no portal Positive News

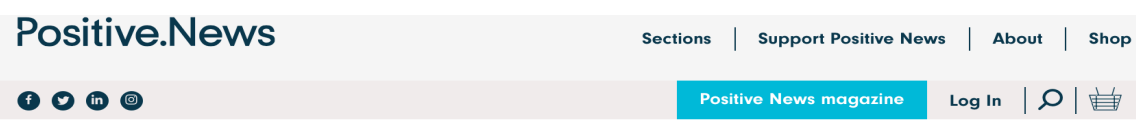

\section{0 ways to help others during the coronavirus outbreak}
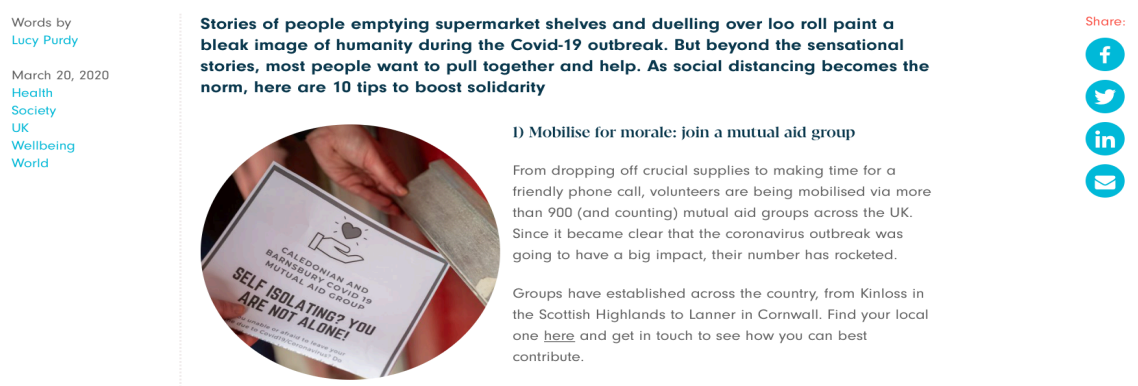

Fonte:https://www.positive.news/society/10-ways-to-help-others-during-the-coronavirus-outbreak/

\footnotetext{
${ }^{6}$ Disponível no seguinte endereço: https://www.positive.news.
} 
SBPJor - Associação Brasileira de Pesquisadores em Jornalismo

$18^{\circ}$ Encontro Nacional de Pesquisadores em Jornalismo

3 a 6 de Novembro de 2020

Espera-se que, com isso, sejam compreendidos os ecos de humanidade nas palavras do jornalismo, e que sejam acentuadas as marcas de sua associação formativa à vida cívica. Por comunicação, referimo-nos a todo e qualquer processo de partilha simbólica que dá início a um vínculo mais ou menos duradouro (seja pelo cruzamento semântico de expressões cuja referência nos inclina à comunhão ou pela consolidação de sentimentos que resgatam a bondade que há em nós). Essa definição, um tanto restrita, tem por propósito delimitar um espectro científico à nossa análise, sem pretensão alguma de percorrer o âmbito de outras áreas do conhecimento ou de esgotar as suas possibilidades interpretativas.

Para se ajustar aos parâmetros teóricos deste trabalho, o conceito de esperança é articulado em relação à ênfase normativa do fenômeno comunicacional - embora não a ponto de se confundirem numa única espessura analítica - , pois nos interessa a constituição de uma perspectiva conceitual que torne possível pensar e falar sobre ambos.

\section{A questão da esperança}

Quando nos referimos à história do jornalismo, salta-nos ao olhar a ideia de que sua trama é o resultado da ordenação de outras narrativas que se ergueram à luz ou que ficaram pelo caminho no trajeto de conversas cívicas. A informação, porém, não precisa se instituir no adensamento da distância entre o mundo e o cidadão — apartando na espessura dizível a pessoa humana —, pois é possível amparar e acolher por meio de um repertório de sentidos e de palavras que revelam os traços da esperança no trabalho jornalístico.

O conceito de esperança exige cuidado, sobretudo por não se referir - ao menos não segundo a dimensão teórica que aqui propomos - às sinalizações morais de cunho religioso. É certo que no inglês antigo, por exemplo, a ênfase do vocábulo "hopian" (o qual mais tarde dá forma à palavra "hope") se articula em função da virtude teológica da espera pela salvação ou da confiança na misericórdia de Deus, sendo então traduzido como "confiar", "crer", "assumir algo com segurança". Sua origem ancestral, por conseguinte, deriva da unidade mínima "hupnojan" — que no proto-indo-europeu significa "saltar" - , e é base às variações linguísticas dos sistemas de representação registrados pelos povos ao redor do mar do Norte (tais como o frísio antigo e o próprio anglo- 
saxão). Não por acaso, aliás, a imagem do salto é associada à força da fé, sugerindo a entrega sincera diante do abismo. É a partir do século XIII que a noção de esperança passa a assumir a semântica do desejo, sobretudo no que pese a "querer profundamente" o que não está ao nosso alcance, embora tenha sido, por pelo menos cem anos antes, evocada para referir-se à confiança no futuro. Não pretendemos esgotar as possibilidades conceituais desse exercício filológico, naturalmente, mas nos interessa a apropriação dessa expectativa construtiva diante do que ainda não aconteceu para situá-la no coração da cidadania, isto é, adensá-la onde em seu lugar há desamparo e onde o "salto" já não parece possível devido às injustiças sociais. Trata-se, portanto, de circunscrevê-la no repertório de sentidos do jornalismo a ponto de "construir um futuro eticamente mais justo, politicamente mais democrático, esteticamente mais irradiante e espiritualmente mais humanizador" (FREIRE, 2013, p. 12-13). Tal como ajeitada neste texto, afinal, a esperança é uma necessidade ontológica.

O relevo do acontecimento surpreendente - traduzido pela linguagem da "notícia ruim" (CHARAUDEAU, 2010, p. 20) — aos poucos dá lugar a uma configuração mais humana às conversas da sociedade, isto é, a um princípio normativo segundo o qual a comunicação se efetiva no vínculo entre a palavra do jornalismo e a vida do cidadão. Isso é evocado de modo implícito na estrutura dizível da análise de jornadas para reforçar o seu compromisso com a comunhão de sentidos, de práticas formativas ou de histórias que asseguram a convivência, sendo o símbolo de uma perspectiva "voltada para manter associados valores e dimensões contraditórios" (WOLTON, 2011, p. 26). Trata-se, portanto, da sinalização da humanidade na espessura das tramas jornalísticas.

A variação discursiva de jornalismo que talvez mais se aproxima desses termos - ao menos de modo explícito - é aquela a que se convencionou caracterizar como "construtiva", cujo relevo se torna visível na busca pela solução aos problemas sociais contemporâneos (AITAMURTO; VARMA, 2018) 7 . Não se trata, contudo, de um gênero próprio à notícia, isto é, de um conjunto estável de informações que se conectam pela similitude; e tampouco de uma alternativa provisória à questão do sensacionalismo na mídia, pois se pretende a ser a expressão de um dever normativo distinto, o qual susten-

\footnotetext{
${ }^{7}$ Eis porque optamos pela coleta e análise das notícias veiculadas no portal Positive News, o qual se assume "construtivo" em seu discurso. Por extrapolar o escopo deste trabalho, deixaremos para outros contextos acadêmicos o estudo teórico da construtividade jornalística.
} 
ta o ideal de progresso cívico com base em "práticas de reportagem orientadas à esperança” (ibid., p. 696) ${ }^{8}$. É nesse ponto que o seu propósito, uma vez que se torna consciente a si mesmo, consolida-se ao abrir clareiras a uma sociedade mais justa e humana.

O que se mostra relevante à questão epistemológica da esperança, afinal, é tornála pensável e dizível na composição normativa de uma atividade jornalística senciente, a qual não apenas intui sobre os ânimos sociais como também serve de ponte entre valores humanos e a cidadania. Por sentimento, aliás, referimo-nos à regulação do envolvimento que nos faz tornar preciosas as coisas da realidade à nossa volta (HELLER, 1999), isto é, que nos convoca a agir de modo mais ou menos inclinado à escuta empática e à estima por qualquer coisa: um processo, uma situação, uma pessoa ou até mesmo outro sentimento (ibid., p. 15-16). Envolver-se, porém, não implica tomar distância do discernimento ou da racionalidade que circunscreve o jornalismo numa dimensão de análise crítica, mas sim permitir-se responsavelmente à compaixão que faz do cidadão o que lhe há de mais caro.

Também não se trata de associar a regulação do envolvimento com a esperança a um tipo de jornalismo subjetivo ou idiossincrático, pois o ponto é lhe atribuir à espessura da palavra um projeto comunicativo de compaixão - o qual se efetiva na abertura às realidades do cidadão. Desse modo é possível associar sua validade racional à questão da alteridade, sem perder o rigor esperado quando se narra o mundo ao Outro. Segundo essa perspectiva, a comunicação não é apenas uma atividade humana, mas a ação que em nós inaugura a própria humanidade. Fazer com que o cidadão se sinta parte dos relatos é uma condição de possibilidade à formação de agrupamentos que se articulam em função de um sentimento, de um ideal, de princípios ou até mesmo da inclinação aos problemas de outras sociedades.

O estudo de processos comunicativos que encontram seu caminho à luz no espaço de circulação simbólica de sentidos do jornalismo interessa não apenas à compreensão das relações humanas, como também, e talvez de modo menos explícito, à constituição de um parâmetro social segundo o qual o respeito mútuo se torna o elemento de-

\footnotetext{
${ }^{8}$ Tradução livre a partir do trecho original em inglês: "reporting practices oriented around hope".
} 
finidor da relação humana (TEMER; TUZZO, 2016) ${ }^{9}$. Se o propósito das narrativas jornalísticas é adensar os laços de humanidade no plano da cidadania — algo que extrapola a mera urgência ou eficácia da informação —, é de se esperar que sua palavra seja o elo fundador de uma existência compartilhada, a qual também revela o adensamento da responsabilidade sob a forma de esperança pronunciável que aos poucos se torna um bem sensível ao qual podemos aspirar.

A aparição de um novo saber, todavia, não implica a substituição do conjunto de conhecimentos e de princípios normativos que antes serviram de norte à atividade jornalística. Pelo contrário, inclusive: ele "remaneja suas posições, suas relações e suas funções” (MOUILLAUD, 2002, p. 203) ${ }^{10}$. Se até aqui delineamos o aspecto epistemológico da esperança, resta-nos então observar o modo como ela é evocada na dimensão textual dos relatos cotidianos, isto é, como adquire significação na espessura de uma narrativa mais humana e solidária. É preciso, de início, perscrutar a superfície léxica dos textos informativos, tendo em vista que toda palavra é atravessada por uma "existência socialmente sustentada" (AUTHIER-REVUZ, 1990, p. 27), e que sua ênfase abre passagens a uma ecologia da alteridade.

Isso posto, convém agora articular a sinalização da esperança em função de um tipo de relato que faça da pessoa humana o eixo principal das preocupações jornalísticas, e assim demonstrar pelo método a especificidade de um repertório que consolida a disposição de sua abertura às realidades do cidadão. É nesse ponto que a questão de uma narrativa esperançosa se converte em chave epistemológica para abordar o jornalismo em sua pretensão comunicativa.

\section{Da abordagem metodológica}

Para compreender as marcas da esperança e as da solidariedade que assinalam a ligação social do jornalismo com o cidadão na superfície dos próprios repertórios, é necessário analisar o seu conteúdo visível a ponto de articulá-lo em função de um arran-

\footnotetext{
${ }^{9}$ Cf. TEMER, A. C.; TUZZO, S. Revisão crítica da relação entre a comunicação e a cidadania: um estudo sobre a mídia. In: SIGNATES, L.; MORAES, Â. Cidadania comunicacional: teoria, epistemologia e pesquisa. Goiânia: Gráfica UFG, 2016. Cap. 6, p. 149-170.

${ }^{10}$ Cf. MOUILLAUD, M. Le Monde e Libération em perspectiva - uma tendência: Libération. In: , M.; PORTO, S. D. O jornal: da forma ao sentido. 2. ed. Brasília: Editora Universidade de Brasília, 2002. Cap. 10, p. 202-213.
} 
jo minimamente teorizável; e assumir, de saída, que "por trás de toda categorização pragmática e operacional dos eventos noticiáveis, há diferentes padrões culturais" (SILVA, 2014, p. 133) ${ }^{11}$ que atravessam a tessitura dos relatos cotidianos. Por conteúdo jornalístico, aliás, referimo-nos ao conjunto de tópicos e de instrumentos metodológicos diversificados que se alinham em relação a uma composição discursiva maior. Eis porque analisá-lo requer uma espécie de hermenêutica dedutiva que orienta uma operação intelectual distintiva, qual seja: a da inferência. Inferir é organizar e compreender os dados em relevo a partir da identificação de tendências e de padrões expressos (CAMPOS, 2010) na própria espessura do conteúdo, atendo-se não na descrição em si, mas naquilo a que se pode aprender diante do que nos revela (BARDIN, 2011).

Como forma de analisar o conteúdo expresso na superfície do portal de notícias construtivas Positive News e articulá-lo em função das características que explicitam na dimensão do texto o registro da esperança e o da solidariedade, portanto, a pesquisa que deu origem a este trabalho foi conduzida em três fases, sendo elas: a) uma pré-análise destinada à seleção dos documentos informativos do corpus para leitura flutuante; b) a exploração do material por meio do software de análises de conteúdo Iramuteq ${ }^{12}$, dedicada então às operações de codificação em função de regras já formuladas com base na superfície textual das matérias; c) e por fim o tratamento dos resultados, a fim de interpretar, inferir, validar e tornar inteligível o conjunto de espessuras linguísticas analisadas.

Uma vez concluída a primeira fase, restou saber em que medida o repertório dizível do portal analisado se alinhava devidamente à questão epistemológica da esperança, isto é, a maneira como o seu vocabulário se ajusta e se permite à construção de um saber mais humano no plano da cidadania. O conteúdo de superfície textual foi traduzido do inglês ${ }^{13}$, sendo então classificado para isolar e reagrupar as unidades registradas em conjuntos de tópicos similares segundo a forma e organização das suas tematizações. É nesse ponto que demos início à classificação hierárquica descendente (CHD)

\footnotetext{
${ }^{11}$ Cf. SILVA, M. P. D. A significância social como dimensão da noticiabilidade. In: SILVA, G.; M. P. D.; FERNANDES, M. L. Critérios de noticiabilidade: problemas conceituais e aplicações. Florianópolis: Insular, 2014. Cap. 6, p. 115-135.

${ }^{12}$ Desenvolvido pelo Laboratoire d'Études et de Recherches Appliquées en Sciences Sociales da Universidade de Toulouse, no sul da França.

${ }^{13}$ É provável que, devido à localização da tradução, alguns significados explícitos tenham se perdido, embora preservadas ao máximo possível as particularidades de seus contextos linguísticos originais.
} 
gerada pelos parâmetros estatísticos do Iramuteq, a qual consiste na distribuição das palavras expressas nas matérias jornalísticas analisadas em classes regulares e de acordo com temáticas em comum. Os segmentos de texto (STs) foram então correlacionados formando assim um esquema em escala de agrupamentos nomeados —, o que tornou possível distribuir a frequência das palavras mais relevantes do corpus e assim gerar um teste qui-quadrado $\left(\chi^{2}\right)^{14}$ para trazer à luz as regularidades de um repertório que conforta e que ampara o cidadão em tempos de desesperança. O banco de dados foi construído a partir de variáveis qualitativas nominais - caracterizadas pela sessão de seu registro e tituladas pelo próprio Positive News —, sendo por fim consideradas numa sequência de 1 a 7 e em respeito à seguinte lógica: 1 = "Ambiente", 2 = "Sociedade", 3 = "Mundo", 4 = "Ciência", 5 = "Estilo de Vida", 6 = "Saúde" e 7 = "Pessoas esperançosas". Os resultados são expressos pelo organograma abaixo:

Figura 2 - Classificação e correlação de frequências da superfície textual do portal Positive News

\begin{tabular}{|c|c|c|c|c|c|c|c|c|c|c|c|}
\hline & & & \multicolumn{9}{|c|}{ Corpus textual - Positive News (341 de 413 STs - Aproveitamento: $82,57 \%$ ) } \\
\hline \multirow{2}{*}{\multicolumn{3}{|c|}{$\begin{array}{c}\text { Classe 1 } \\
\text { Ponto de partida: } \\
12,61 \%-43 \text { STs }\end{array}$}} & \multirow{2}{*}{\multicolumn{3}{|c|}{$\begin{array}{c}\text { Classe 2 } \\
\text { Ponto de partida: } \\
31,09 \%-106 \mathrm{STs}\end{array}$}} & \multirow{2}{*}{\multicolumn{3}{|c|}{$\begin{array}{c}\text { Classe } 3 \\
\text { Ponto de partida: } \\
41,64 \%-142 \text { STs }\end{array}$}} & \multirow{2}{*}{\multicolumn{3}{|c|}{$\begin{array}{c}\text { Classe } 4 \\
\text { Ponto de partida: } \\
14,66 \%-50 \text { STs }\end{array}$}} \\
\hline & & & & & & & & & & & \\
\hline \multicolumn{3}{|c|}{$\begin{array}{c}\text { Variáveis: } \\
\text { Pessoas esperancosas }\left(S=5 ; \chi^{2}=2,18\right) \\
\text { Mundo }\left(=24 ; \chi^{2}=2,25\right) \\
\text { Estilo de vida }\left(\mathcal{S}=9 ; \chi^{2}=2,57\right)\end{array}$} & \multicolumn{3}{|c|}{$\begin{array}{c}\text { Variáveis: } \\
\text { Saúde }\left(\mathcal{S}=20 ; \chi^{2}=2,53\right) \\
\text { Sociedade }\left(\mathcal{S}=9 ; \chi^{2}=7,51\right)\end{array}$} & \multicolumn{3}{|c|}{$\begin{array}{l}\text { Variáveis: } \\
\text { Ambiente }\left(f=14 ; \chi^{2}=8,5\right) \\
\text { Ciência }\left(f=29 ; \chi^{2}=12,24\right) \\
\text { Mundo }\left(S=80 ; \chi^{2}=12,27\right)\end{array}$} & \multicolumn{3}{|c|}{$\begin{array}{l}\text { Variáveis: } \\
\text { Saúde }\left(S=46 ; \chi^{2}=9,95\right)\end{array}$} \\
\hline Repertório & 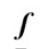 & $\chi^{2}$ & Repertório & $\boldsymbol{f}$ & $\chi^{2}$ & Repertório & $\boldsymbol{f}$ & $\chi^{2}$ & Repertório & $f$ & $\chi^{2}$ \\
\hline Considerar & 7 & 49,53 & Pessoa & 53 & 48,53 & Coronavírus & 39 & 23,33 & Gratuito & 9 & 36,19 \\
\hline Próximo & 7 & 41,69 & Ajudar & 29 & 22,44 & Reduzir & 6 & 8,56 & Bondade & 4 & 23,56 \\
\hline Continuar & 4 & 28,05 & Chamado & 8 & 18,16 & Humano & 5 & 7,11 & Mental & 10 & 33,91 \\
\hline Positivo & 5 & 22,44 & Isolar & 9 & 16,69 & Enfrentar & 7 & 7,09 & Refugiado & 5 & 23,02 \\
\hline Necessitar & 3 & 14,03 & Precisar & 15 & 13,41 & Trabalhar & 10 & 6,92 & Apoiar & 8 & 16,75 \\
\hline Receber & 4 & 12,86 & Criar & 13 & 13,09 & Mútuo & 4 & 5,67 & Possível & 4 & 13,02 \\
\hline Doar & 3 & 10,34 & Participar & 6 & 9,96 & Mobilizar & 4 & 5,67 & Bem-estar & 6 & 12,41 \\
\hline Querer & 6 & 7,41 & Voluntário & 10 & 7,73 & Futuro & 4 & 5,67 & Oferecer & 9 & 10,76 \\
\hline Fazer & 10 & 7,29 & Compartilhar & 9 & 7,51 & Combater & 4 & 5,67 & Arrecadar & 2 & 2,6 \\
\hline Poder & 15 & 5,31 & Fornecer & 9 & 4,96 & Unido & 18 & 4,56 & Sobreviver & 2 & 2,6 \\
\hline
\end{tabular}

Fonte: elaborado pelos autores

\footnotetext{
${ }^{14}$ Teste estatístico que consiste na avaliação das probabilidades previstas de um evento dizível qualquer — articulado, evidentemente, em relação à consistência de uma distribuição teórica particular.
} 
Foram aproveitados $82,57 \%$ dos STs do corpus - porque excluídas as palavras e demais termos que em nada alterariam a inferência do repertório investigado (sobretudo conjunções, artigos e outras unidades linguísticas maiores) - , contemplando apenas as dez ocorrências ( $\int$ ) mais significativas analisadas em 341 dos 413 STs da pesquisa. O critério de seleção amostral foi estabelecido de maneira não-probabilística para considerar somente a veiculação de notícias durante o período da primeira onda de contágio do coronavírus, e com base nisso foram criadas quatro classes distintas que revelam na dimensão do conteúdo a inclinação humana de um repertório jornalístico mais sensível às realidades do cidadão.

A classe 1, chamada de "Tendência altruística", corresponde à análise de 43 STs $(12,61 \%)$, e é composta pelas variáveis "Mundo", "Estilo de Vida" e "Pessoas Esperançosas". Seu repertório se manifesta através de palavras como "considerar", "próximo", “necessitar", “doar" e "positivo". Se articulada em função do contexto em que é evocada, aliás, esta última diz respeito à possibilidade de realização do que se pretende alcançar, e não ao estado psicológico de sentir-se ou querer-se bem. Essa classe é afinal construída a partir dos sentidos expressos por uma certa urgência de bondade e de amparo ao próximo:

\begin{abstract}
Ao doar para eles, você pode ajudar a instituição de caridade a atender mais ligações em sua linha de aconselhamento e também fazer "ligações de amparo" regulares às pessoas que ficam sozinhas durante o auto-isolamento do coronavírus. (POSITIVE NEWS, 2020, s/p) ${ }^{15}$.

"Encontre oportunidades para ampliar histórias positivas e esperançosas". Esse foi um dos conselhos sobre saúde mental dados pela Organização Mundial da Saúde no início da pandemia. À medida que prossegue a crise do coronavírus, histórias de esperança nunca foram tão importantes; servindo de contrapeso a um ciclo de notícias ininterruptas que podem parecer desoladoras. [...] Em resposta, o Positive News, que se concentra em histórias sobre progresso e soluções, quer oferecer cópias de sua revista impressa a profissionais de saúde em todo o Reino Unido. (POSITIVE NEWS, 2020, s/p) ${ }^{16}$.
\end{abstract}

\footnotetext{
15 Trecho extraído e traduzido da matéria: "10 ways to help others during the coronavirus outbreak", publicada em 20 de março de 2020 e disponível no seguinte endereço: https://www.positive.news/society/10-ways-to-help-othersduring-the-coronavirus-outbreak/. Acesso em 22/03/2020.

${ }^{16}$ Extraído e traduzido da matéria: "Crowdfunding campaign to get Positive News magazine to NHS workers", publicada em 23 de abril de 2020 e disponível no seguinte endereço:

https://www.positive.news/lifestyle/health/crowdfunding-campaign-to-get-positive-news-magazine-to-nhs-workers/. Acesso em 25/04/2020.
} 
Esses trechos da amostra revelam uma força ilocucionária no conteúdo jornalístico analisado, isto é, uma tendência sincera à compaixão - expressa então por funções pragmáticas diretivas que são representadas na forma de conselhos ao cidadão e de disposições de abertura às suas realidades. A pretensão de afetividade se efetiva numa linguagem que torna admissível "exercitar-se na ternura, acariciando 'com a palavra', sem que a solidez argumentativa perca sua força" (KÜNSCH, 2010, p. 19) ${ }^{17}$.

A classe 2, denominada "Dever cívico", foi criada com base no aproveitamento de 106 STs (31,09\% do corpus analisado), e considera as variáveis "Saúde" e "Sociedade". Seu repertório é afinal composto por palavras como "pessoa", "ajudar", "chamado" e "voluntário", sendo então caracterizada pelo apelo explícito a um compromisso social com o cidadão em tempos de crise:

Há uma tradição no teatro que diz: sempre que vazio, resta uma luz - eis porque as pessoas retornam. Nas últimas duas semanas, essa "luz fantasmagórica" foi acesa não apenas nos cinemas, mas em museus, galerias, salas de concertos e em cinemas durante um fechamento sem precedentes que muitos temiam ser catastrófico às artes e ao meio de vida de seus muitos participantes. (POSITIVE NEWS, 2020, s/p) ${ }^{18}$.

[...] à medida que o governo aconselha as pessoas a ficarem em casa, é improvável que algumas empresas locais sobrevivam. Outras, porém, sobreviverão, e é possível apoiar aquelas que, em sua comunidade, significam tanto para você. Muitas estão oferecendo vales-presente, o que lhes dará um aumento de renda a curto prazo, ao passo que você terá a perspectiva esperançosa de usá-los quando a vida voltar a um estado que se aproxime do normal. (POSITIVE NEWS, 2020, s/p) ${ }^{19}$.

Nesses trechos, a linguagem jornalística se inclina a uma condição de existência mais amorosa e altruísta, revelando na superfície dos textos a presença do cidadão enquanto uma dimensão constitutiva de seu repertório. A compreensão ativa e responsiva em relação às situações sociais vividas pode então servir como uma pretensão de vínculo duradouro entre o jornalismo e a sociedade.

\footnotetext{
${ }^{17}$ Cf. KÜNSCH, D. Comunicação e pensamento compreensivo: um breve balanço. In: , D.; SÁ MARTINO, L. M. (Orgs.). Comunicação, jornalismo e compreensão. São Paulo: Editora Plêiade, 2010. Cap. 1, p. 13-47.

${ }^{18}$ Trecho extraído e traduzido da matéria: "Coronavirus: how arts and culture are fighting back", publicada em 20 de março de 2020 e disponível no seguinte endereço: https://www.positive.news/lifestyle/arts/coronavirus-how-arts-andculture-are-fighting-back/. Acesso em 22/03/2020.

${ }^{19}$ Trecho extraído e traduzido da matéria: "10 ways to help others during the coronavirus outbreak", publicada em 01 de abril de 2020 e disponível no seguinte endereço: https://www.positive.news/society/10-ways-to-help-othersduring-the-coronavirus-outbreak/. Acesso em 02/04/2020.
} 


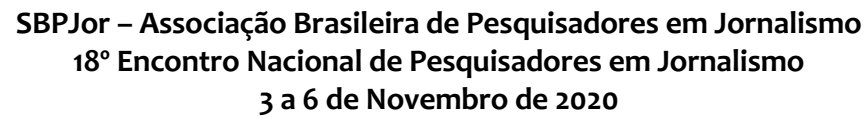

A classe 3, aqui chamada de "Mobilização social", aproveita 41,64\% do corpus amostral, o que corresponde a 142 STs. As variáveis consideradas foram as de "Ambiente", "Ciência" e "Mundo", e seu repertório é composto por palavras como "Coronavírus", "trabalhar", "mobilizar" e "humano". Essa classe está associada à urgência de se pensar em mecanismos de entre-ajuda eficientes ao combate da pandemia:

Mais de 200 grupos de "ajuda mútua” surgiram em todo o Reino Unido para apoiar aqueles que sofrem com os efeitos e a ameaça do surto de coronavírus. $\mathrm{Na}$ tarde de domingo, 249 grupos haviam sido estabelecidos em todo o Reino Unido para ajudar as pessoas afetadas pela Covid-19 (ou as que se isolam) numa tentativa de evitar o vírus. (POSITIVE NEWS, 2020, s/p). ${ }^{20}$

Em todo o Reino Unido, dezenas de indivíduos, departamentos acadêmicos e empresas comerciais estão colaborando para projetar e fabricar ventiladores que podem salvar a vida de pessoas que sofrem por conta da Covid-19. Muitos estão trabalhando incessantemente no que foi descrito como um "esforço de guerra" sem precedentes. (POSITIVE NEWS, 2020, s/p). ${ }^{21}$

O padrão noticioso, portanto, não se consolida no mero relato de acontecimentos passados ou presentes, mas sim, e sobretudo, na construção de uma narrativa que expõe e que incentiva em algum grau possível a busca por uma transformação social compartilhada.

A classe 4, por fim, associa a variável "Saúde" a um repertório de palavras como "gratuito", "bondade", "bem-estar" e "sobreviver". É denominada "Agir solidário", e corresponde à análise de 50 STs (14,66\% do corpus), sendo então caracterizada pela orientação sincera e responsável à piedade humana:

Com a diferença tangível que promove na vida das crianças refugiadas, a instituição de caridade, bem como as demais organizações, são exemplos fantásticos da bondade para com as pessoas e para com o planeta que é tão valioso no momento. (POSITIVE NEWS, 2020, s/p). ${ }^{22}$

\footnotetext{
${ }^{20}$ Trecho extraído e traduzido da matéria: "Communities vs Covid-19: hundreds of neighborly support groups spring up”, publicada em 17 de março de 2020 e disponível no seguinte endereço: https://www.positive.news/society/communities-vs-covid-19-hundreds-of-neighbourly-support-groups-spring-up/. Acesso em 18/03/2020.

${ }^{21}$ Trecho extraído e traduzido da matéria: “'Wartime effort': The people working all hours to make ventilators for the NHS", publicada em 9 de abril de 2020 e disponível no seguinte endereço:

https://www.positive.news/science/wartime-effort-the-people-working-all-hours-to-make-ventilators-for-the-nhs/. Acesso em 10/04/2020.

${ }^{22}$ Trecho extraído e traduzido da matéria: “'Our need for joy is greater than ever': Clowns Without Borders wins Kindness Awards" publicada em 6 de abril de 2020 e disponível no seguinte endereço: https://www.positive.news/society/our-need-for-joy-is-greater-than-ever-clowns-without-borders-wins-kindnessawards/. Acesso em 8/04/2020.
} 
SBPJor - Associação Brasileira de Pesquisadores em Jornalismo

$18^{\circ}$ Encontro Nacional de Pesquisadores em Jornalismo

3 a 6 de Novembro de 2020

Com a crise do coronavírus afetando a saúde mental dos trabalhadores da linha de frente, o Positive News fornecerá a eles cópias gratuitas de sua revista, para apoiar o seu bem-estar. (POSITIVE NEWS, 2020, s/p) ${ }^{23}$.

A linguagem é menos austera quando comparada àquela das narrativas jornalísticas referenciais, embora não perca a sua validade objetiva por pretender-se à exposição explícita da cooperação. Considerando as quatro classes que dão coerência aos dados da pesquisa, portanto, talvez seja possível entrever nos relatos cotidianos do Positive News uma tentativa de articular a esperança, a solidariedade e a empatia em função de uma bondade emancipatória no plano da cidadania.

\section{Algumas considerações}

Gostaríamos de ajeitar as últimas costuras com duas proposições que muito traduzem o que nos revelou esta pesquisa, quais sejam: a de que comunicar é "aceitar a experiência da alteridade" (WOLTON, 2006, p. 225) e a de que olhar "significa também tomar conta de, cuidar de, zelar por" (MAFFESOLI, 2009, p. 95). Com isso reforçamos esse propósito ilocucionário do jornalismo, evocando-lhe uma visão que (re)conhece a vida e que não se acanha em dividir afetos no plano da cidadania. Ao firmar com a pessoa humana a ênfase de um diálogo social — em cuja ancoragem é sinalizada não apenas a urgência da verdade, mas também a do amor e a da bondade —, cria-se um centro reflexivo onde a sociedade se torna capaz de pronunciar um saber sobre si mesma, fazendo então da esperança o elo que nos forma e que nos convoca à união de todos com todos em tempos de novos horizontes éticos. A esperança é, portanto, um elemento fundante do ato de conhecer, e como tal há de adensar no repertório de sentidos jornalísticos a tendência do estar-junto.

\section{Referências}

AITAMURTO, T.; VARMA, A. The constructive role of journalism. Journalism Practice, v. 12 , n. 6, p. 695-713, ago. 2018.

\footnotetext{
${ }^{23}$ Extraído e traduzido da matéria: "Crowdfunding campaign to get Positive News magazine to NHS workers", publicada em 23 de abril de 2020 e disponível no seguinte endereço:

https://www.positive.news/lifestyle/health/crowdfunding-campaign-to-get-positive-news-magazine-to-nhs-workers/. Acesso em 25/04/2020.
} 
SBPJor - Associação Brasileira de Pesquisadores em Jornalismo

$18^{\circ}$ Encontro Nacional de Pesquisadores em Jornalismo

3 a 6 de Novembro de 2020

AUTHIER-REVUZ, J. Heterogeneidade(s) Enunciativa(s). Caderno de Estudos Linguísticos, Campinas, v. 19, p. 25-42, Jul/Dez 1990.

BARDIN, L. Análise de conteúdo. 1. ed. São Paulo: Edições 70, 2011.

CAMPOS, D. C. A análise de conteúdo na pesquisa qualitativa. In.: ; BAPTISTA, M.

Metodologias de pesquisa em ciências. Rio de Janeiro: LTC, 2010.

CHARAUDEAU, P. Discurso das mídias. Tradução de Angela M. S. Corrêa. 2. ed. São Paulo: Contexto, 2010.

FREIRE, P. Pedagogia da esperança: um reencontro com a pedagogia do oprimido. 1. ed. rio de Janeiro: Paz e Terra, 2013.

HABERMAS, J. O discurso filosófico da modernidade. Tradução de Ana Maria Bernardo [et al.]. 2. ed. Lisboa: Publicações Dom Quixote, 1998.

HELLER, A. Teoría de los sentimientos. México: Ediciones Coyoacán, 1999.

KÜNSCH, D.; SÁ MARTINO, L. M.; (Orgs.). Comunicação, jornalismo e compreensão. São Paulo: Editora Plêiade, 2010.

MAFFESOLI, M. A república dos bons sentimentos. Tradução de Ana Goldberger. São Paulo: Iluminuras, 2009.

MOUILLAUD, M.; PORTO, S. D. O jornal: da forma ao sentido (coleção comunicação). Tradução de Sérgio Grossi Porto. 2. ed. Brasília: Editora Universidade de Brasília, 2002.

SIGNATES, L.; MORAES, Â. Cidadania comunicacional: teoria, epistemologia e pesquisa. Goiânia: Gráfica UFG, 2016.

SILVA, G.; SILVA, M. P. D.; FERNANDES, M. L. Critérios de noticiabilidade: problemas conceituais e aplicações. Florianópolis: Insular, 2014.

TRAQUINA, N. Jornalismo: questões, teorias e “estórias”. 2. ed. Lisboa: Vega, 1999.

WOLTON, D. É preciso salvar a comunicação. São Paulo, SP: Paulus, 2006.

, D. Informar não é comunicar. Porto Alegre: Sulina, 2011. 